\title{
Promoting physical activity and health literacy: study protocol for a longitudinal, mixed methods evaluation of a cross- provider workplace-related intervention in Germany (The AtRisk study)
}

\author{
Andrea Schaller ${ }^{1,2^{*}}$, Lea Dejonghe ${ }^{2}$, Adrienne Alayli-Goebbels ${ }^{3}$, Bianca Biallas ${ }^{2}$ and Ingo Froboese Fi $^{2,4}$
}

\begin{abstract}
Background: Physical activity and health literacy are topics of utmost importance in the prevention of chronic diseases. The present article describes the study protocol for evaluating a cross-provider workplace-related intervention promoting physical activity and health literacy.

Methods: The RE-AIM Framework will be the conceptual framework of the AtRisk study. A controlled natural experiment and a qualitative study will be conducted. The cross-provider intervention is based on the cooperation of the German Pension Fund Rhineland and cooperating German Statutory Health Insurances. It combines two components: a behavior-oriented lifestyle intervention and the assignment of a health coach. The single-provider intervention only includes the behavior-oriented lifestyle intervention.

The quantitative study (natural experiment) encompasses three measuring points ( $\mathrm{T} 0=$ start of the behavior-oriented lifestyle intervention (baseline); $\mathrm{T} 1$ = end of the behavior-oriented lifestyle intervention (16 weeks); T2 = 6 month follow-up) and will compare the effectiveness of the cross-provider workplace-related intervention compared with the single provider intervention. Participants are employees with health related risk factors. ANCOVA will be used to evaluate the effect of the intervention on the outcome variables leisure time physical (primary outcome) activity and health literacy (secondary outcome). The qualitative study comprises semi-structured interviews, systematic field notes of stakeholder meetings and document analyses.
\end{abstract}

Discussion: The AtRisk study will contribute towards the claim for cross-provider interventions and workplace-related approaches described in the new Preventive Health Care Act. The results of this study will inform providers, payers and policy makers about the effectiveness of a cross-provider workplace-related lifestyle intervention compared to a single-provider intervention. Beyond, the study will identify challenges for implementing cross-provider preventive interventions. With respect to the sustainability of preventive interventions the AtRisk study will give insight in the expectations and needs on health coaching from the perspective of different stakeholders.

Trial registration: DRKS00010693.

Keywords: Health promotion, Cross-provider, Workplace, Physical activity, Health literacy

\footnotetext{
* Correspondence: a.schaller@dshs-koeln.de

${ }^{1}$ IST University of Applied Sciences, Erkrather Str. 220 a-c, Düsseldorf 40233,

Germany

${ }^{2}$ Institute of Health Promotion and Clinical Movement Science, German Sport

University Cologne, Am Sportpark Muengersdorf 6, Cologne 50933, Germany

Full list of author information is available at the end of the article
} 


\section{Background}

Chronic diseases constitute the main cause of mortality and morbidity in the European Union [1]. Around $50 \%$ of the populations in the age of 30 to 49 years suffer from one or more chronic diseases [2]. The demands on workers' health have increased substantially due to skilled worker shortage, globalization, prolongation of working lifetime and transition to flexible working conditions. Hence, the prevention of chronic diseases to ensure employability is of high individual and socioeconomic importance [3-8].

It is widely known that influencing health contributes to a person's well-being, quality of life, health status, workability and performance [9]. Health coaching offers opportunities for an individualized and sustainable prevention, especially by interconnecting aspects of behavior-oriented and condition-oriented (e.g. workplace) aspects and facilitating the client's learning process by using professional methods and techniques $[10,11]$. Within health promotion physical activity and health literacy are topics of utmost importance. Evidence shows that sedentary behavior is associated with an increased risk of premature all-cause and cardiovascular disease mortality and elevated biomarkers of cardio metabolic risk, including waist circumference, blood glucose, systolic blood pressure, and serum triglycerides [12-14]. Health literacy is a core competence and a high level of health literacy is considered of substantial benefit for maintaining one's health $[15,16]$. Health literacy describes a person's knowledge and competence to meet the complex demands of health in modern society [16]. Several studies have already demonstrated the relationship of low health literacy, poor health status $[9,17,18]$ and higher health care costs $[19,20]$.

The new Preventive Health Care Act in Germany points out the importance of workplace-related health promotion and calls for cross-provider interventions, e.g. cooperation of the German Statutory Health Insurance and the German Pension Fund. However, experiences on the capabilities and challenges of a crossprovider intervention are lacking. The present article describes the research protocol for the evaluation of a cross-provider workplace-related intervention promoting physical activity and health literacy. The specific objectives include (i) the evaluation of the effectiveness of a cross-provider workplace-related lifestyle intervention compared to a single-provider intervention; (ii) gaining understanding of the implementation of the cross-provider workplace-related lifestyle intervention during the study period; (iii) the identification of facilitators and barriers in cross-provider collaboration; as well as (iv) the identification of different stakeholders' expectations and demands regarding health coaching.

\section{Methods/design}

It is assumed that the cross-provider workplace-related intervention improves leisure time physical activity and health literacy compared to the single-provider intervention in persons who are at risk for chronic diseases.

\section{Research design and conceptual framework}

The design and research questions of the AtRisk study were guided by the RE-AIM Framework [21]. The REAIM Framework is based on system-based and socioecological thinking and enables an overall assessment of the impact of the intervention. It has been specifically developed to facilitate the evaluation of interventions in real-world settings. The model identifies five evaluation dimensions: the Reach, the Efficacy or Effectiveness, the Adoption, the Implementation and the Maintenance of a public health intervention. The five RE-AIM dimensions occur at different levels, e.g. the individual, the organizational or the community level. Reach is defined as an individual-level measure of participation and refers to the percentage and risk characteristics of the participants. Efficacy or Effectiveness refers to the impact of an intervention on important intervention-specific outcomes, including potential negative effects, quality of life, and economic outcomes. Adoption refers to the proportion and representativeness of settings, e.g., such as worksites, health providers and/or payers, that adopt a given program or intervention. The Implementation refers to the extent to which a program is delivered as intended. At the setting level, implementation refers to the intervention providers' fidelity to the various elements of an intervention's protocol, including consistency of the delivery as intended and the time and cost of the intervention. Finally, the dimension Maintenance refers to the extent to which a program becomes institutionalized or part of the routine organizational practices and policies. Beyond, maintenance also refers to the individual level and has been defined as the longterm effects of a program on outcomes after six or more months after the most recent intervention contact [21]. Table 1 provides a description of the research questions for each of the five RE-AIM dimensions. The research questions will be answered by means of a mixed methods design combining quantitative and qualitative data sources. Quantitative data regarding intervention effectiveness will be collected using various questionnaires as part of a natural experiment. Qualitative data will be collected by means of supplementary interviews, informal field notes and document studies.

\section{The cross-provider intervention}

The cross-provider intervention is based on the cooperation of the German Pension Fund Rhineland and cooperating German Statutory Health Insurances. It 
Table 1 Research questions and analytic approaches

\begin{tabular}{|c|c|}
\hline Research question & Analytic approach \\
\hline \multicolumn{2}{|l|}{ Reach } \\
\hline \multirow{2}{*}{$\begin{array}{l}\text { 1. How many persons participate in the intervention? } \\
\text { 2. By what means were the participants recruited? }\end{array}$} & Quantitative study \\
\hline & Qualitative study \\
\hline \multicolumn{2}{|l|}{ Effectiveness } \\
\hline \multirow{2}{*}{$\begin{array}{l}\text { 1. Is there a difference in leisure time physical activity between the cross-provider intervention and the } \\
\text { control intervention? } \\
\text { 2. Is there a difference in health literacy between the intervention and the control intervention? }\end{array}$} & Quantitative study \\
\hline & Quantitative study \\
\hline \multicolumn{2}{|l|}{ Adoption } \\
\hline \multirow{3}{*}{$\begin{array}{l}\text { 1. How many providers offer the cross-provider intervention? } \\
\text { 2. How many companies cooperate in the cross-provider intervention? } \\
\text { 3. How many statutory social insurers cooperate in the cross-provider intervention? }\end{array}$} & Qualitative study \\
\hline & Qualitative study \\
\hline & Qualitative study \\
\hline \multicolumn{2}{|l|}{ Implementation } \\
\hline \multirow{4}{*}{$\begin{array}{l}\text { 1. Is the intervention conducted according to the manual? } \\
\text { 2. What are the facilitators and barriers for the cross-provider intervention? } \\
\text { 3. What are the different stakeholders' expectations and needs regarding health coaching in a work-related setting? } \\
\text { 4. What are costs associated with implementation for the different stakeholders? }\end{array}$} & Qualitative study \\
\hline & Qualitative study \\
\hline & Qualitative study \\
\hline & Qualitative study \\
\hline \multicolumn{2}{|l|}{ Maintenance } \\
\hline \multirow{3}{*}{$\begin{array}{l}\text { 1. Is there a difference in leisure time physical activity between the cross-provider intervention and the control } \\
\text { intervention at six month follow-up? } \\
\text { 2. Is there a difference in health literacy between the intervention and the control intervention at six month follow-up? } \\
\text { 3. What structures resources were built in companies, providers and social insurers to implement the cross-provider } \\
\text { intervention in daily routine? }\end{array}$} & Quantitative study \\
\hline & Quantitative study \\
\hline & Qualitative study \\
\hline
\end{tabular}

incorporates the cooperating companies and combines two components: A) a behavior-oriented lifestyle intervention (for all participants) and B) assignment of a health coach (optional). The following components are offered within the comprehensive cross-provider health prevention service:

A) Standardized behavior-oriented lifestyle intervention (all participants)

The German Pension Fund Rhineland finances a lifestyle intervention that comprises three phases: the initial-phase (three days), the training-phase (16 weeks) and a refresher day after 6 month of self-guided exercise (one day). The intervention is provided in four authorized ambulatory rehabilitation centres placed in North Rhine Westphalia, Germany (Fig. 1).

The initial-phase comprises three days (or $16 \mathrm{~h}$ ) and includes the assessment of the participants' health status, the drawing up of an individual job-related requirement profile and the introduction into the aims and contents of the complete intervention and the subsequent training phase. The extraoccupational training phase is a behaviour-related preventive intervention comprising 32 trainings, 105 min each. The trainings are conducted twice a week over the duration of 16 weeks. The training phase combines theoretical and practical approaches and aims at a health-enhancing lifestyle change. The focus areas are physical activity, stress regulation and nutritional behaviour. The manual describes 15 theoretical sessions, 45 min each, spanning the subject areas of nutrition, physical activity, resilience and stress regulation. The 17 practical sessions comprise endurance training, coordination training, strengthening training with small devices and workplace related training sessions (45 min per session). In addition, medical training therapy is conducted at each of the 32 trainings (32 sessions, $60 \mathrm{~min}$ ).

Six months after the end of the training phase, the refresher day aims at the reflection of the participants regarding the lifestyle changes in daily routine. Individual barriers and facilitators are discussed with the group and the multiprofessional team.

The maximum group size is 15 participants. To ensure the structure quality and the process quality of the behaviour-related preventive intervention is conducted by a multiprofessional team (sport scientists, psychologist, nutrition consultant) in an authorized ambulatory rehabilitation centre. To ensure the standardization of the preventive service, the content and structure of the intervention is based on a guideline and described explicitly in part two of 


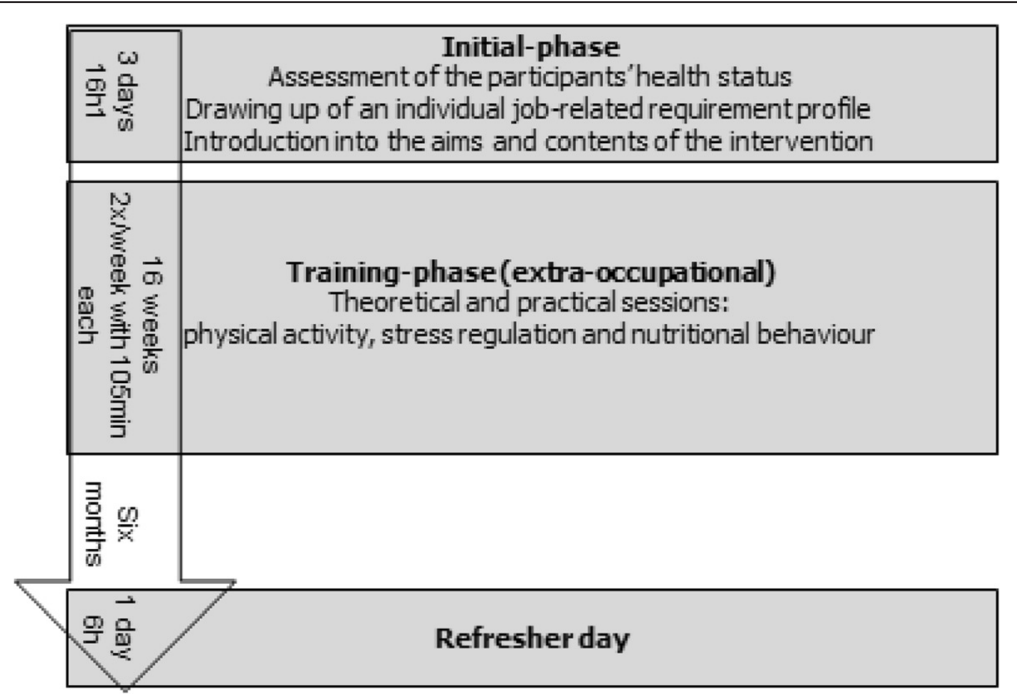

Fig. 1 The behavior-related intervention of the German Pension Fund Rhineland (component A)

Präventionsleistungen der Deutschen Rentenversicherung Rheinland. Ein konzeptioneller Leitfaden ([22]).

B) Personalized health coaching (optional)

The cooperating statutory health insurances are financing the health coach. The health coach supports the participant during the entire period of the behavior-related lifestyle intervention (see A) and explicitly gives individual support between the end of the training phase and the refresher day (selfguided exercise). Health coaching focuses education, coaching and guidance of the participant. Health coaching is conducted by the means of face-to-face contact, telephone and e-mail contact. The superior aim of health coaching is bridging the interface between the behavior-related intervention (see A) and the workplace (see C). Beyond, health literacy and self-efficacy of the participant is supported. Frequency and content of health coaching varies according to the phase of the behavior-related intervention (see A) and the individual needs of the participant. For more information on the work of the health coach see Präventionsleistungen der Deutschen Rentenversicherung Rheinland. Ein konzeptioneller Leitfaden ([22]).

\section{Quantitative study}

The quantitative study of AtRisk is a non-randomised controlled trial. The controlled trial made use of a natural experiment in which the implementation and delivery of the intervention was not manipulated by researchers. Instead, the allocation to one of the two possible conditions compared in this study (cross-provider intervention: A) and B); single-provider intervention: A)) is given according to the real world condition. If the statutory health insurance of the participant signed cooperation with German Pension Fund Rhineland in regard to preventive health services, the participant was allocated to the cross-provider intervention. Otherwise, the participant was allocated to the control group (single-provider intervention).

The AtRisk study compares the cross-provider intervention with a single provider intervention and encompasses three measuring points: $\mathrm{T} 0=$ start of the behavior-oriented lifestyle intervention (baseline); $\mathrm{T} 1=$ end of the behavior-oriented lifestyle intervention; $\mathrm{T} 2=$ 6 month follow-up (see Fig. 2).

The study was approved by the German Sport University Cologne Ethics Committee (reference number: 93/ 2015) and registered in the German Clinical Trials Register (ID: DRKS00010693). Written informed consent is taken from each participant. The recruitment of participants started in July 2016 and will be completed in August 2017. Six months follow-up (T2) will be completed in January 2018.

\section{Participants}

The study population comprises employees with health related risk factors. Eligible participants were invited from the company doctor to participate in the behaviorrelated intervention (component A). The company doctor conducts the medical entry examination and the participant makes an application for the preventive measure at the German Pension Fund ( $\$ 31$ Social Code Book $\mathrm{VI}$ ). The corresponding forms for the participant (G0180 and G0185) and the medical report of the company doctor (G0190) can be downloaded [23]. The application is approved by the German Pension Fund Rhineland. Eligibility criteria for participating in the present study is (1) 


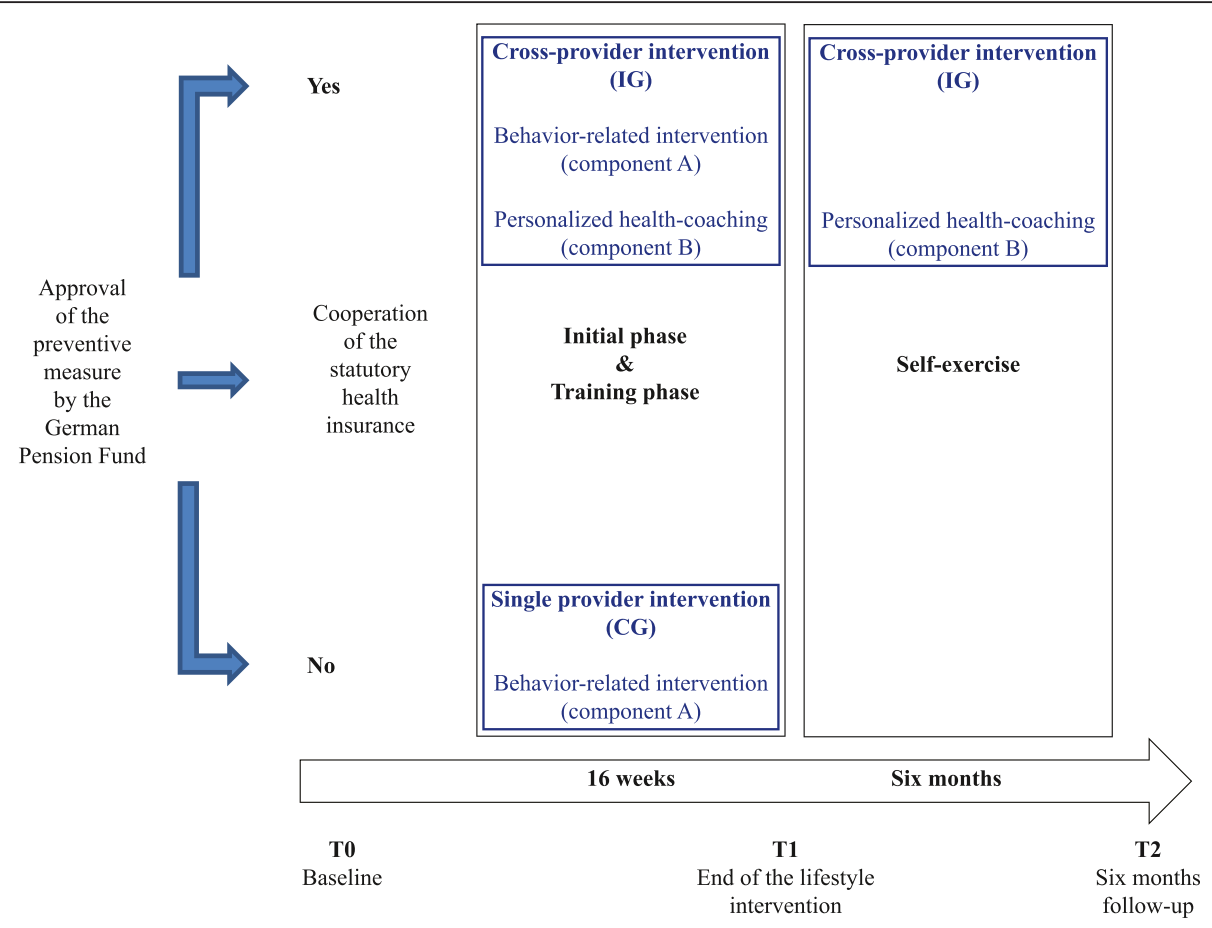

Fig. 2 Allocation and study design

a formally approved application for a preventive health service by the German Pension Fund, (2) age 18 to 65 years, (3) First health impairments (of the musculoskeletal system, internal organs or mental impairments) (4) written informed consent to participate in the study. Exclusion criteria are: (1) The indication for a rehabilitative treatment; (2) the need for acute care; (4) lack of understanding the German language.

\section{Outcome measurements}

The participants answer a questionnaire on physical activity, health literacy, health-related quality of life and sociodemographic variables. The baseline questionnaire (T0) is answered at the beginning of the initial phase. The questionnaire at the end of the training phase (T1) and the 6 month follow-up questionnaire (T2) are collected using a postal questionnaire.

We chose leisure physical activity $\left(\mathrm{MET}^{1}\right.$-min/week) as our primary outcome. Physical activity was operationalized by the Global Physical Activity Questionnaire [3, 24], which collects information on both physical activity during a typical week within three settings (workplace, transport and leisure time) as well as on sedentary behaviour. Activity specific scores are summed to give the total MET-min/ week. Thereby, each minute of vigorous physical activity is multiplied by 8 METs and each minute of moderate physical activity by 4 METs. Bull et al. (2009) showed a moderate to strong positive relationship of the Global Physical Activity Questionnaire with the International Physical
Activity Questionnaire (concurrent validity: Spearman's rho $0.45-0.65$ ), and the reliability was of moderate to substantial strength (kappa 0.67 to 0.73 ; Spearman's rho 0.67 to 0.81) [3]. Compared to the accelerometer data, the Global Physical Activity Questionnaire provided low-to-moderate validity and generally acceptable evidence of reliability [25].

The secondary outcome measurement of the AtRisk study is health literacy. We assessed health literacy by the questionnaire from Lenartz [15] that is based on the definition of health literacy, representing "[...] the cognitive and social skills which determine the motivation and ability of individuals to gain access to, understand and use information in ways which promote and maintain good health." ([26], p. 357). Lenartz (2012) developed a structure model explaining health behavior and health through the influence of individual basic competences (health-related knowledge, health-related skills and beneficial personality triats) and further developed abilities and skills. Based on this model, the health literacy scale from Lenartz comprises 30 items assessing six abilities and skills: self-regulation (5 items), self-control (5 items), self-perception (5 items) and responsibility (5 items), communication and cooperation (5 items) and the handling of health information (5 items) [15]. Each item has four response options"not correct at all", "rather not correct", "rather correct", "correct" (Fig. 3).

Additionally, the domain „Actively managing my health"of the Health Literacy Questionnaire (HLQ) is used [27]. This domain contains five items ("I spend 


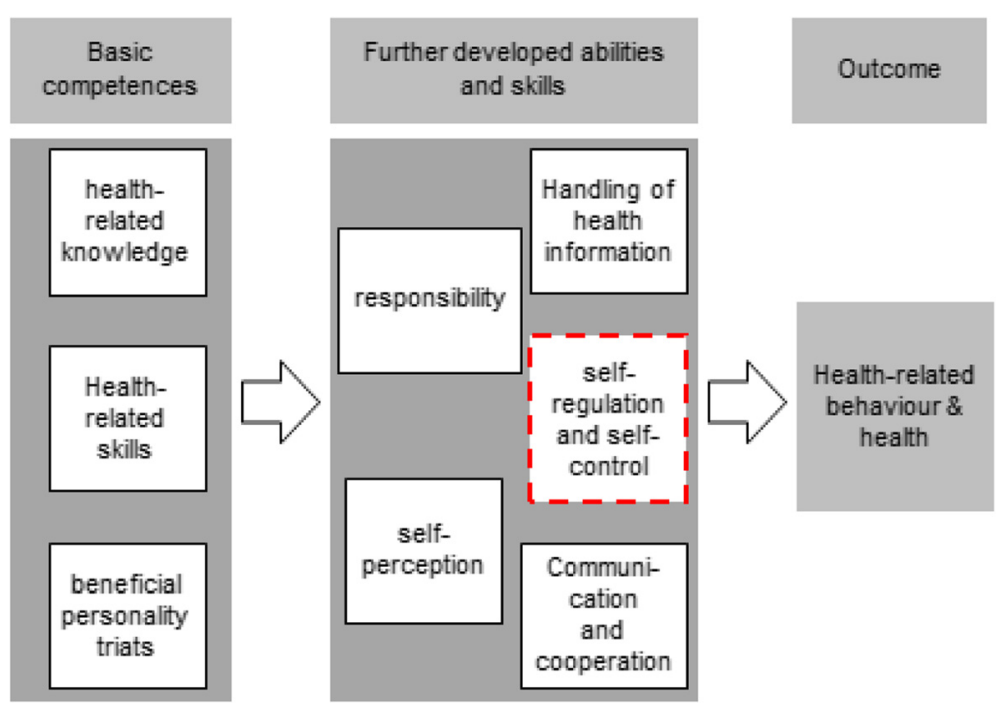

Fig. 3 Structure model: further developed abilities and skills of health literacy (\{Lenartz 2012 \#4\}, p. 120)

quite a lot of time actively managing my health"; "I make plans for what I need to do to be healthy"; "Despite other things in my life, I make time to be healthy"; "I set my own goals about health and fitness"; "There are things that I do regularly to make myself more healthy") measured by a four point likert-scale (strongly disagree, disagree, agree and strongly agree). The scale score is devised by summing the item scores and dividing by the number of items in the scale [27].

\section{Further variables}

For obtaining person-related variables, age, sex, height, weight, education level, family status and health-related lifestyle were assessed by unstandardized questions. Beyond, health-related Quality (HRQoL) of life was measured using the EQ-5D-5 l questionnaire [28]. The EQ-5D is a standardized measure of health status and assesses five dimensions of HRQoL: mobility, self-care, daily activities, pain and discomfort, anxiety or depression. EQ-5D-5 L provides five levels for answering each dimension: "no problems", "slight problems", "moderate problems", "severe problems" and "extreme problems". Descriptive answers were converted into a single summary index [29]. Index value of health status range from ' 1 ' (perfect health) to ' 0 ' (death). Beyond, workability was assessed by the work ability index (WAI) [30, 31] employability was measured by the 3-item subjective prognosis of gainful employment (SPE-scale) [32-34]. Overall, the following instruments are used (Table 2).

\section{Statistical analysis}

Descriptive statistics will be used to describe the baseline characteristics of study population and to explore the distributions of the variables at the individual level.
Depending on the distributions of the quantitative variables parametric and non-parametric tests are used to compare the intervention and the control group at baseline.

The two study groups will be compared using ANCOVA, with the outcome variables leisure time physical (primary outcome) activity and health literacy (secondary outcome), at 6 month follow-up set as the dependent variable [35]. Baseline values and the rehabilitation center will be used as a covariate to control for imbalance between control and intervention groups at baseline.

Standardized mean-difference effect size will be calculated by using the means of the two groups, meansquare error and the correlation between the covariate and dependent variable.

Intervention outcomes will be evaluated in relation to the base case data but also to the intention to treat principle. The base-case analysis will be performed using data restricted to those patients who replied to the postal 6 month follow-up questionnaire. The intentionto-treat analysis $\left(\mathrm{ITT}_{\mathrm{LOCF}}\right)$ will be performed assuming "last observation carried forward" since the effectiveness of physical activity promotion is considered controversial [36-38]: if 6 month follow-up data (T2) were missing, it was assumed that the physical activity data were the same as at baseline (T0). The statistical analyses will be conducted independently of the research team. The data will be analyzed using the statistical software IBM Statistics 23.0.

The calculated total sample size is 237 (ANCOVA: Fixed effects, main effects and interactions; Input: effect size $\mathrm{f}=0.25$ with $80 \%$ power at $\mathrm{p}<0.05$; number of groups $=8$ (group $=2$; ambulatory rehabilitation center 
Table 2 Summary of measures

\begin{tabular}{|c|c|c|}
\hline & Instrument & Time of measurement ${ }^{a}$ \\
\hline \multicolumn{3}{|l|}{ Primary outcome measure } \\
\hline Physical Activity & GPAQ Questionnaire $([3,24])$ & $\mathrm{TO}, \mathrm{T} 1, \mathrm{~T} 2$ \\
\hline \multicolumn{3}{|l|}{ Secondary outcome measure } \\
\hline \multirow[t]{2}{*}{ Health literacy } & Health literacy scale ([15]) & $\mathrm{T} 0, \mathrm{~T} 1, \mathrm{~T} 2$ \\
\hline & HLQ Subscale „Actively managing my health“([27]) & \\
\hline \multicolumn{3}{|l|}{ Person-related variables } \\
\hline Age, sex, height, weight, & Unstandardized questionnaire & T0 \\
\hline Education level, family status & Unstandardized questionnaire & T0 \\
\hline Health-related lifestyle & Unstandardized questionnaire & $\mathrm{TO}, \mathrm{T} 1, \mathrm{~T} 2$ \\
\hline Health Related Quality of Life & EQ-5D-5 L ([28]) & $\mathrm{T} 0, \mathrm{~T} 1, \mathrm{~T} 2$ \\
\hline \multicolumn{3}{|l|}{ Work-related variables } \\
\hline Workability & Work ability questionnaire $([30,31])$ & $\mathrm{T} 0, \mathrm{~T} 1, \mathrm{~T} 2$ \\
\hline Employability & subjective prognosis of gainful employment (SPE-scale) (Mittag 2003 \#57\}; [33, 34]) & $\mathrm{T} 0, \mathrm{~T} 1, \mathrm{~T} 2$ \\
\hline
\end{tabular}

${ }^{\mathrm{a}} \mathrm{T} 0=$ initial phase (baseline); $\mathrm{T} 1=$ End of training-phase; $\mathrm{T} 2$ = six month follow-up

$=4$ ); numerator $\mathrm{df}=7$; number of covariates $=2$ (age; baseline value)). Therefore, it is estimated that a sample size of 119 participants per study arm would be required to detect a medium effect between the cross-provider intervention and the single-provider intervention. To allow for missing data and loss to follow up, we aim to recruit 150 participants per study arm.

\section{Qualitative study}

The qualitative study comprises semi-structured interviews, systematic field notes of stakeholder meetings and document analyses. Semi-structured interviews and field notes will be conducted to explore the questions in regard to the RE-AIM dimensions implementation ("What are the facilitators and barriers for the cross-provider intervention?"; "Is the intervention conducted according to the manual?"; "What are the different stakeholders' expectations and needs regarding health coaching in a work-related setting?"; "What are costs associated with implementation for the different stakeholders?") and maintenance ("What structures resources were built in companies, providers and social insurers to implement the cross-provider intervention in daily routine?") (see Table 1). The different stakeholders involved in the intervention (German Pension Fund Rhineland, cooperating statutory health insurers, providers, healthcoaches, participants, company doctors and company management) will participate in the semi structured interviews.

In regard to health-coaching the semi-structured interviews encompass the perspectives of different stakeholders. Amongst others, the aim is to get information on tasks and objectives of health coaching, the necessary qualification, skills and competences of a health coach as well as the working methods and main topics in health coaching. The interview partners will be interviewed personally once, using semi-structured qualitative interviews. Two researchers lead through the semi-structured interviews: one will lead the conversation and the other one will do the documentation. If the participants agree, the interviews will be audio recorded. All semi-structured interviews will be in German. After the interviews are completed, transcriptions will be done according to the rules of Kuckartz [39]. Transcriptions will be double-checked.

The transcripts will be analysed according to the structuring content analysis by Mayring [40], which is similar to the framework approach [41]. For the analysis a qualitative research specialist at German Sport University Cologne, Germany will use the software MAXQDA 12 in order to code the information and look for relevant trends and themes within the data. Common themes and issues will be grouped together in main- and subcategories and frequencies will be noted in order to highlight key issues. Though this is a qualitative study, the frequencies will be reported. However, direct quotations will be pulled from the session reports when they are illustrative of the issues. Overall, around 15 interviews will be included in this study, approximately two interviews per stakeholder group. Beyond, field notes of protocols of conversations with stakeholders (German Pension Fund Rhineland, statutory health insurances, health coaches, therapists and managers of ambulatory rehabilitation centers) and documents will be considered to gain insight into the dimension adoption ("How many providers offer the cross-provider intervention?"; "How many companies cooperate in the cross-provider intervention?"; "How many statutory social insurers cooperate in the cross-provider intervention?") and implementation ("Is the intervention conducted according to the manual?"). 


\section{Discussion}

The study presented is designed to evaluate the effectiveness and the challenges of a workplace-related crossprovider intervention. Beyond, the expectations and needs on health coaching are of particular interest.

The study took as its starting point the new Preventive Health Care Act in Germany and its claim on crossprovider preventive measures [42, 43]. The second starting point of the study was significance and also the challenges of workplace-related health promotion. Despite the importance of workplace-related health promotion, the feasibility and the effectiveness are widely debated $[24,44]$. On the one hand, the workplace is suitable reaching workers with health-risks for preventive measures [45-47]. On the other hand, participation rates in health promotion interventions at the workplace are low [25]. Overall, studies relating to workplace interventions are of high heterogeneity concerning interventions as well as population groups and therefore rarely comparable [48]. Nevertheless, study results support the superiority of multimodal interventions including ergonomic, behavior-related and workplace-related aspects compared to single interventions [49]. Workplace-related interventions should be multimodal and tailored to the needs and the preventive competence of both, the individuals and the organizations [50].

In regard to practical implications results may be relevant because of the clear orientation in employees with health-related risk factors. Since most studies focus mixed populations and do not differentiate interventions aiming at populations at risk and healthy persons [51] it is essential not only to develop but also to evaluate interventions with the ability to reach employees focusing on those who need it most $[25,51]$. Hence, especially persons with health related risk factors (e.g. physical inactivity), people with a low socioeconomic status and men show a low rate of preventive activities [52, 53]. Beyond, the evaluation of the effectiveness of health coaching in regard to the sustainability of the preventive lifestyle measure is of high practical relevance. The study contributes to the professionalization in the field of health coaching not only by the evaluation of its effectiveness but also by the semi-structured interviews with different stakeholders providing a more profound understanding of the potential, challenges and qualification needs in health coaching.

There are several challenges in conducting this study. First, the present evaluation is performed in a real-life setting. This is a strength, on the one hand, because this provides a realistic estimate of effectiveness. On the other hand, several methodological challenges arise. Workplace-related interventions as well as studies promoting physical activity are fraught with methodological difficulties. Evidence development is considered a big challenge in prevention and health promotion [54-57]. Measures in health promotion are mainly complex interventions in complex socio-ecological systems [58] and several dimensions of complexity exist, for example the range of possible outcomes, the outcome variability in the target population and the number of elements in the intervention package itself [59]. Irrespective of the mode of intervention, evaluation of the impact therefore underlies high methodological standards and needs to consider three perspectives: multiplicity, context sensitivity and complexity as a reference point [56]. Although for many decades randomized controlled experiments have dominated the impact assessment of social or health programs, there are many arguments that stress the artificiality of these approaches as well as the lack of useful information produced [60, 61]. The World Health Organization even concluded that "the use of randomized control trials to evaluate health promotion initiatives is, in most cases, inappropriate, misleading and unnecessarily expensive" ([62], p. 5).

Realistic evaluation considers the complexity of health interventions and it may help to meet the challenges of evaluation in health promotion aiming at finding out how a program works, for whom and under what circumstances. The RE-AIM Framework provides a useful template to guide the design and implementation of a cross-provider intervention as it allows concurrent evaluation of dimensions considered relevant to 'real world' implementation.

The use of mixed methods within the research project enables a more complete picture of the intervention, its effectiveness and finding out how the intervention works, for whom and under what circumstances [63].

\section{Endnotes}

${ }^{1}$ The metabolic equivalent (MET) is a physiological measure expressing the expended energy of physical activities. MET is defined as the ratio of the rate of energy consumption during a specific physical activity to a reference metabolic rate.

\section{Funding}

This study is funded by the Federal Ministry of Education and Research (BMBF). BMBF project number: 01EL1425A. The AtRisk study is a project conducted from the research association TRISEARCH.

\section{Availability of data and materials}

The datasets during and/or analysed during the current study are available from the corresponding author on reasonable request.

\section{Authors' contributions}

AS designed and wrote the original proposal supported by BB. AS developed further the study design supported by AA and LD. AS wrote the manuscript supported by LD, BB and AA. LD is responsible for data collection and the qualitative study. AS is responsible for data analysis and drafting of the final research report, supported by LD, BB and AA. All authors 
participated in discussing the design of the study and developing the research protocol. All authors have read and approved the final manuscript.

\section{Competing interests}

The authors declare that they have no competing interests.

\section{Consent for publication}

Not applicable.

\section{Ethics approval and consent to participate}

The Ethics Committee of the German Sport University Cologne has approved the study. Written informed consent is taken from each participant. A copy of the signed consent form as well and contact information is delivered to each participant.

\section{Author details}

${ }^{1}$ IST University of Applied Sciences, Erkrather Str. 220 a-c, Düsseldorf 40233, Germany. ${ }^{2}$ Institute of Health Promotion and Clinical Movement Science, German Sport University Cologne, Am Sportpark Muengersdorf 6, Cologne 50933, Germany. ${ }^{3}$ Institute of Health Economics and Clinical Epidemiology (IGKE), University of Cologne, Gleuelerstr. 176-178, Cologne 50935, Germany. ${ }^{4}$ Center for Health and Physical Activity, German Sport University Cologne, Am Sportpark Muengersdorf 6, Cologne 50933, Germany.

Received: 1 July 2016 Accepted: 9 July 2016

\section{Published online: 22 July 2016}

\section{References}

1. World Health Organization (WHO). Global Status Report on Noncommunicable Diseases 2010. Geneva: World Health Organization; 2011.

2. Varekamp I, van Dijk FJH, Kroll LE. Workers with a chronic disease and work disability. Problems and solutions. Bundesgesundheitsblatt Gesundheitsforschung Gesundheitsschutz. 2013:56:406-14.

3. Bishop K, Phillips A, Thow AM. Chronic disease and participation in work Canberra: Australian Institute of Health and Welfare; 2009.

4. Center for Disease Control and Prevention. The Power of Prevention. Chronic disease... the public health challenge of the 21st century; 2009.

5. Sommer I, Griebler U, Mahlknecht P, Thaler K, Bouskill K, Gartlehner G, Mendis S. Socioeconomic inequalities in non-communicable diseases and their risk factors: an overview of systematic reviews. BMC Public Health. 2015;15:914

6. Schwartz FW, Abelin T. Das Public-Health-Buch: Gesundheit und Gesundheitswesen. 2nd ed. München [u.a.]: Urban \& Fischer; 2003.

7. van Rijn RM, Robroek SJW, Brouwer S, Burdorf A. Influence of poor health on exit from paid employment: a systematic review. Occup Environ Med. 2014:71:295-301.

8. Varekamp I, van Dijk FJH. Workplace problems and solutions for employees with chronic diseases. Occupational medicine (Oxford, England). 2010;60: 287-93.

9. Berkman ND, Sheridan SL, Donahue KE, Halpern DJ, Crotty K. Low health literacy and health outcomes: an updated systematic review. Ann Intern Med. 2011;155:97-107.

10. Frates EP, Moore MA, Lopez CN, McMahon GT. Coaching for behavior change in physiatry. American journal of physical medicine \& rehabilitation/ Association of Academic Physiatrists. 2011:90:1074-82.

11. Wolever RQ, Caldwell KL, Wakefield JP, Little KJ, Gresko J, Shaw A, Duda LV, Kosey JM, Gaudet T. Integrative health coaching: an organizational case study. Explore (NY). 2011;7:30-6.

12. Dunstan DW, Salmon J, Healy GN, Shaw JE, Jolley D, Zimmet PZ, Owen N. Association of television viewing with fasting and 2 -h postchallenge plasma glucose levels in adults without diagnosed diabetes. Diabetes Care. 2007;30: 516-22.

13. Healy GN, Dunstan DW, Salmon J, Shaw JE, Zimmet PZ, Owen N. Television time and continuous metabolic risk in physically active adults. Med Sci Sports Exerc. 2008; $40: 639-45$

14. Thorp AA, Healy GN, Owen N, Salmon J, Ball K, Shaw JE, Zimmet PZ, Dunstan DW. Deleterious associations of sitting time and television viewing time with cardiometabolic risk biomarkers: Australian Diabetes, Obesity and Lifestyle (AusDiab) study 2004-2005. Diabetes Care. 2010;33:327-34.

15. Lenartz N. Gesundheitskompetenz und Selbstregulation. Göttingen: V\&R unipress; 2012 [Applied Research in Psychology and Evaluation, vol. 6].
16. Sørensen K, Van den Broucke S, Fullam J, Doyle G, Pelikan J, Slonska Z, Brand $\mathrm{H}$. Health literacy and public health: a systematic review and integration of definitions and models. BMC Public Health. 2012;12:80.

17. Cho YI, Lee SD, Arozullah AM, Crittenden KS. Effects of health literacy on health status and health service utilization amongst the elderly. Soc Sci Med. 2008:66:1809-16.

18. Sentell T, Braun KL. Low health literacy, limited English proficiency, and health status in Asians, Latinos, and other racial/ethnic groups in California. Jealth Commun. 2012;17 Suppl 3:82-99.

19. Baker DW, Gazmararian JA, Williams MV, Scott T, Parker RM, Green D, Ren J, Peel J. Functional Health Literacy and the Risk of Hospital Admission Among Medicare Managed Care Enrollees. Am J Public Health. 2002;92: 1278-83.

20. Howard DH, Gazmararian J, Parker RM. The impact of low health literacy on the medical costs of Medicare managed care enrollees. Am J Med. 2005; 118:371-7.

21. Glasgow RE, Vogt TM, Boles SM. Evaluating the Public Health Impact of Health Promotion Interventions: The RE-AIM Framework. Am J Public Health 1999;89:1322-7.

22. German Pension Fund Rhineland. Präventionsleistungen der Deutschen Rentenversicherung Rheinland. Ein konzeptioneller Leitfaden. Düsseldorf: NOW IT GmbH; 2013.

23. Deutsche Rentenversicherung: Formulare \& Anträge. Index: nach Formularnummer [http://www.deutsche-rentenversicherung.de/Allgemein/ de/Navigation/5_Services/04_formulare_und_antraege/06_gesamt/G_ formulare_node.html].

24. Goetzel RZ, Henke RM, Tabrizi M, Pelletier KR, Loeppke R, Ballard DW, Grossmeier J, Anderson DR, Yach D, Kelly RK, McCalister T, Serxner S, Selecky C, Shallenberger LG, Fries JF, Baase C, Isaac F, Crighton KA, Wald P, Exum E, Shurney D, Metz RD. Do workplace health promotion (wellness) programs work? J Occup Environ Med. 2014;56:927-34.

25. Robroek SJ, van Lenthe FJ, van Empelen P, Burdorf A. Determinants of participation in worksite health promotion programmes: a systematic review. Int J Behav Nutr Phys Act. 2009:6:26.

26. Nutbeam D. Health promotion glosssary. Health Promot Int. 1998;13:349-64.

27. Osborne RH, Batterham RW, Elsworth GR, Hawkins M, Buchbinder R. The grounded psychometric development and initial validation of the Health Literacy Questionnaire (HLQ). BMC Public Health. 2013;13:658.

28. Herdman M, Gudex C, Lloyd A, Janssen M, Kind P, Parkin D, Bonsel G, Badia X. Development and preliminary testing of the new five-level version of EQ-5D (EQ-5D-5 L). Qual Life Res Int J Qual Life Asp Treat Care Rehab. 2011;20:1727-36.

29. van Reenen M, Janssen B. EQ-5D-5 L User Guide: Basic information on how to use the EQ-5D-5 L instrument Version 21. Rotterdam: EuroQol Research Foundation; 2015

30. IImarinen J, Tempel J. Arbeitsfähigkeit. Hamburg: VSA Verlag; 2002.

31. de Zwart BCH. Test-retest reliability of the Work Ability Index questionnaire. Occup Med. 2002:52:177-81.

32. Mittag $\mathrm{O}$, Raspe $\mathrm{H}$. A brief scale for measuring subjective prognosis of gainful employment: findings of a study of 4279 statutory pension insurees concerning reliability (Guttman scaling) and validity of the scale. Rehabilitation. 2003:42:169-74.

33. Theissing J, Lepthin $\mathrm{H}$, Mittag $\mathrm{O}$. Modification of the subjective prognosis of gainful employment during inpatient rehabilitation. Findings of a study of 180 orthopaedic patients. Rehabilitation. 2005;44:75-81.

34. Mittag O, Glaser-Möller N, Ekkernkamp M, Matthis C, Héon-Klin V, Raspe A Raspe H. Prädiktive Validität einer kurzen Skala zur subjektiven Prognose der Erwerbstätigkeit (SPE-Skala) in einer Kohorte von LVA-Versicherten mit schweren Rückenschmerzen oder funktionellen Beschwerden der inneren Medizin. Soz Praventivmed. 2003;48:361-9.

35. Vickers AJ, ALtman DG. Analysing controlled trials with baseline and follow up measurements. BMJ. 2001;323(7321):1123-4

36. Orrow G, Kinmonth A, Sanderson S, Sutton S. Effectiveness of physical activity promotion based in primary care: systematic review and metaanalysis of randomised controlled trials. BMJ (Clinical research ed). 2012;344:e1389

37. Foster C, Hillsdon M, Thorogood M, Kaur A, Wedatilake T. Interventions for promoting physical activity. Cochrane Database of Systematic Reviews 2005 ssue 1. Art. No.: CD003180. doi: 10.1002/14651858.CD003180.pub2.

38. Lobelo F, Stoutenberg M, Hutber A. The Exercise is Medicine Global Health Initiative: a 2014 update Br J Sports Med. 2014:48(22):1627-33. doi: 10.1136/ bjsports-2013-093080. Epub 2014 Apr 23. 
39. Kuckartz U. Qualitative Evaluation: Der Einstieg in die Praxis. 2nd ed. Wiesbaden: VS, Verl. für Sozialwiss; 2008 [SpringerLink: Bücher].

40. Mayring P. Qualitative Inhaltsanalyse: Grundlagen und Techniken. 11th ed. Beltz: Weinheim; 2010 [Beltz Pädagogik].

41. Der Titel "\#208" kann nicht dargestellt werden - Die Vorlage "Literaturverzeichnis - Zeitschriftenaufsatz - (Standardvorlage)" beinhaltet nur Felder, welche bei diesem Titel leer sind.

42. Bundesministerium für Gesundheit: Bundestag verabschiedet Präventionsgesetz [http://www.bmg.bund.de/ministerium/meldungen/2015/ praeventionsgesetz.html].

43. Gesetz zur Stärkung der Gesundheitsförderung und der Prävention: Präventionsgesetz - PrävG; 2015 [vol. 2015].

44. Soler RE, Leeks KD, Razi S, Hopkins DP, Griffith M, Aten A, Chattopadhyay SK, Smith SC, Habarta N, Goetzel RZ, Pronk NP, Richling DE, Bauer DR, Buchanan LR, Florence CS, Koonin L, MacLean D, Rosenthal A, Matson Koffman D, Grizzell JV, Walker AM. A systematic review of selected interventions for worksite health promotion. The assessment of health risks with feedback. Am J Prev Med. 2010;38:S237-62.

45. MDS: Leistungen der gesetzlichen Krankenversicherung: Primärprävention und betriebliche Gesundheitsförderung.; 2013.

46. Hughes SL, Seymour RB, Campbell RT, Shaw JW, Fabiyi C, Sokas R. Comparison of two health-promotion programs for older workers. Am J Public Health. 2011;101:883-90.

47. Goetzel RZ, Long SR, Ozminkowski RJ, Hawkins K, Wang S, Lynch W. Health, absence, disability, and presenteeism cost estimates of certain physical and mental health conditions affecting U.S. employers, vol. 46. 2004.

48. Rongen A, Robroek SJW, van Lenthe FJ, Burdorf A. Workplace health promotion: a meta-analysis of effectiveness. Am J Prev Med. 2013;44:406-15.

49. Pronk NP. Physical activity promotion in business and industry: evidence, context, and recommendations for a national plan. J Phys Act Health. 2009; 6 Suppl 2:S220-35.

50. Jung J, Nitzsche A, Ansmann L, Ernstmann N, Ommen O, Stieler-Lorenz B, Wasem J, Pfaff H. Organizational factors and the attitude toward health promotion in German ICT-companies. Health Promot Int. 2012;27:382-93.

51. Groeneveld IF, Proper KI, Van Der B, Allard J, Hildebrandt VH, Van Mechelen W. Lifestyle-focused interventions at the workplace to reduce the risk of cardiovascular disease - a systematic review. Scand J Work Environ Health. 2010;36:202-15.

52. Jordan S, von der Lippe E. Angebote der Prävention - Wer nimmt teil? In: Robert Koch Institut, editor. GBE Kompakt. Zahlen und Trends der Gesundheitsberichterstattung des Bundes. 2012.

53. MDS: Präventionsbericht 2015: Leistungen der gesetzlichen Krankenversicherung: Primärprävention und betriebliche Gesundheitsförderung Berichtsjahr 2014; 2015.

54. Ackermann G, Pfyl R. Vom Umgang der Evaluation mit Komplexität, LeGes - Gesetzgebung \& Evaluation. 2010. p. 73-83.

55. Badura B, Ducki A, editors. Erfolgreiche Unternehmen von morgen gesunde Zukunft heute gestalten: Zahlen, Daten, Analysen aus allen Branchen der Wirtschaft; mit 222 Tabellen, vol. 2014. Berlin [u.a.]: Springer; 2014.

56. Bödeker W. Wirkungen und Wirkungsnachweis bei komplexen Interventionen. In: Robert Koch Institut, editor. Evaluation komplexer Interventionsprogramme in der Prävention: Lernende Systeme, lehrreiche Systeme? Beiträge zur Gesundheitsberichterstattung des Bundes. Berlin: Gesundheitsberichterstattung des Bundes; 2012. p. 33-42.

57. Datta J, Petticrew M. Challenges to evaluating complex interventions: a content analysis of published papers. BMC Public Health. 2013;13:568.

58. Robert Koch-Institut, Bayerisches Landesamt für Gesundheit und Lebensmittelsicherheit (Hrsg) Evaluation komplexer Interventionsprogramme in der Prävention: Lernende Systeme, lehrreiche Systeme? Beiträge zur Gesundheitsberichterstattung des Bundes. RKI, Berlin. 2012.

59. Craig P, Dieppe P, Macintyre S, Michie S, Nazareth I, Petticrew M. Developing and evaluating complex interventions: the new Medical Research Council guidance. BMJ (Clinical research ed). 2008;337:a1655.

60. Chen H, Rossi PH. Evaluating With Sense. The Theory-Driven Approach. Eval Rev. 1983;7:283-302
61. Hawe P, Shiell A, Riley T. Complex interventions: how "out of control" can a randomised controlled trial be? BMJ (Clinical research ed). 2004;328:1561-3.

62. WHO. Health promotion evaluation: recommendations to policy-makers: Report of the WHO European Working Group on Health Promotion Evaluation. 1998.

63. Morse JM. Principles of mixed methods and multimethod research design. In: Tashakkori A, Teddlie C, editors. Handbook of mixed methods in social \& behavioral research. Thousand Oaks: SAGE Publications; 2003. p. 189-208.

\section{Submit your next manuscript to BioMed Central and we will help you at every step:}

- We accept pre-submission inquiries

- Our selector tool helps you to find the most relevant journal

- We provide round the clock customer support

- Convenient online submission

- Thorough peer review

- Inclusion in PubMed and all major indexing services

- Maximum visibility for your research

Submit your manuscript at www.biomedcentral.com/submit
Biomed Central 